\title{
Pengolahan Sampah Rumah Tangga Menjadi Kompos di Kelurahan. Labuh Baru Timur Pekanbaru
}

\author{
Ambar Tri Ratna Ningsih*1, Latifa Siswati ${ }^{2}$ \\ 1, Fakultas Kehutanan Universitas Lancang Kuning \\ 2 Fakultas Pertanian Universitas Lancang Kuning \\ *e-mail: ambar@unilak.ac.id
}

\begin{abstract}
A lot of research on composting from household waste has been done and the results of the research show a positive thing, some even become a source of family income. Labuh Baru Timur Village already has a Waste Bank, but to process organic waste into compost, cadres of Waste Banks every RW still do not have that knowledge. The Unilak Community Service Team has the required knowledge, and through this activity knowledge transfer is carried out, so that the Waste Bank Cadre will be more optimal in managing the waste that has been collected in the Waste Bank of each RW. The method of activities given to the community is awareness, counseling, demonstration, and evaluation. Awareness is intended to give awareness to Waste Bank Cadres that managing waste into compost will have a positive impact on their environment. Counseling aims to provide knowledge to the community so that they are more sensitive to their environment so that the environment will provide beneficial results for their families. The demonstration aims to provide knowledge directly, both through picture shows, and the practice of directly composting household waste. And evaluation is carried out to determine the level of knowledge of partners before and after the activity, and to determine the success of the activity. The results of the activities concluded that the participants' knowledge, understanding, and skills could increase ranging from 4\% -95\%. And the composting speed depends on the size of the organic material used as the compost material, the smaller the size of the pieces of organic material, the faster the composting process will be. Bio activators used to play a role in accelerating the composting process, besides the homogeneity of materials is also a consideration in composting..
\end{abstract}

Keywords: Waste, compost, Bio activator

\begin{abstract}
Abstrak
Penelitian tentang pembuatan kompos dari sampah rumahtangga sudah banyak dilakukan dan hasil penelitian menunjukkan hal yang positif, bahkan ada yang menjadi sumber penghasilan keluarga. Kelurahan Labuh Baru Timur sudah memiliki Bank Sampah, tetapi untuk mengolah sampah organik menjadi kompos, kader Bank Sampah setiap RW masih belum memiliki pengetahuan tersebut. Tim Pengabdian Masyarakat Unilak memiliki pengetahuan yang dibutuhkan tersebut, dan melalui kegiatan ini dilakukan transfer pengetahuan, sehingga Kader Bank Sampah akan lebih optimal mengelola sampah yang sudah terkumpul di Bank Sampah masing-masing RW. Metode kegiatan yang diberikan kepada masyarakat adalah, penyadaran, penyuluhan, demonstrasi, dan evaluasi. Penyadaran ditujukan untuk memberikan kesadaran pada Kader Bank Sampah bahwa pengelolaan sampah menjadi kompos akan berdampak positif terhadap lingkungannya. Penyuluhan bertujuan untuk memberikan pengetahuan kepada masyarakat agar mereka lebih peka terhadap lingkungannya, sehingga lingkungan akan memberikan hasil yang bermanfaat bagi keluarganya. Demontrasi bertujuan untuk memberikan pengetahuan secara langsung, baik melalui tayangan gambar, dan praktek langsung membuat kompos dari sampah rumahtangga. Dan evaluasi dilakukan untuk mengetahui tingkat pengetahuan mitra sebelum dan sesudah kegiatan, dan untuk mengetahui keberhasilan kegiatan tersebut. Hasil kegiatan disimpulkan dapat meningkatan pengetahuan, pemahaman, dan ketrampilan peserta berkisar antara 4\%-95\%. Dan kecepatan pengomposan sangat tergantung dari ukuran bahan organik yang dijadikan bahan untuk kompos, semakin kecil ukuran potongan bahan organik maka proses pengomposan akan semakin cepat. Bio aktifator yang digunakan berperan dalam mempercepat proses pengomposan, selain itu kehomogenan bahan juga menjadi pertimbangan dalam pengomposan
\end{abstract}

Kata kunci: sampah, kompos, Bio aktifator 


\section{PENDAHULUAN}

Sampah rumahtangga adalah limbah yang dihasilkan dari kegiatan pengolahan makanan, maupun sampah dari tanaman yang ada disekitar rumah. Pengelolaan sampah yang benar akan menjadikan lingkungan tempat tinggal terlihat lebih bersih, dan sampah yang dikelola dengan baik akan menghasilkan kompos yang dapat digunakan untuk menyuburkan tanah sehingga lingkungan menjadi lebih asri.

Kelurahan Labuh Baru Timur adalah salah satu Kelurahan yang sudah memiliki Bank Sampah, dan Kelurahan ini merupakan Kelurahan yang mendapat penghargaan sebagai Kelurahan bersih. Permasalahan yang dihadapi oleh Kader Bank Sampah adalah minimnya pengetahuan mereka dalam mengelola sampah organik untuk dijadikan kompos, sedangkan bahan untuk pembuat kompos tersedia di sekitar rumah dan dihasilkan dari dapur rumah.

Universitas Lancang Kuning melalui Tim Pengabdian Masyarakatnya memiliki pengetahuan untuk mengolah sampah organik menjadi kompos. Sehingga kegiatan ini dijadikan sebagai sarana untuk mentransfer pengetahuan yang dimiliki ke khalayak umum yang membutuhkan. Berdasarkan kegiatan yang dilakukan oleh (Sulistyorini, 2005) dilaporkan bahwa transfer teknologi kepada masyarakat dapat meningkatkan pengetahuan mereka dalam mengolah sampah menjadi lebih berguna. Kegiatan yang dilakukan oleh (Suprapto, Ali, dan Nuryadin, 2017) menghasilkan kesadaran masyarakat yang meningkat dalam mengelola lingkungannya dari sampah rumah tangga menjadi kompos dan kompos cair. (Sinartani, 2011) melaporkan bahwa sampah organik yang dihasilkan di daerah perkotaan bersifat biodgradable (dapat terurai), sehingga dapat dimanfaatkan, proses penguraiannya biasanya memanfaatkan mikroorganisme pengurai seperti EM-4 dan aktifator lainnya ataupun mikroorganisme pengurai yang ada di dalam tanah.

Pembuatan kompos yang berasal dari sampah dapat digunakan untuk tanaman hias dengan perbandingan 1:1, sedangkan untuk tanaman sayur penambahan kompos yang dihasilkan dari sampah harus diikuti dengan penambahan pupuk anorganik. Kompos daun yang diolah menjadi kompos di lingkungan kampus menjadikan kampus menjadi lebih bersih dan meningkatkan masyarakat kampus untuk berwirausaha, lingkungan menjadi lebih asri dan meningkatkan kesuburan tanah (Setyaningsih, Astuti, Astuti, Biologi, dan Surakarta, 2017). Pembuatan kompos dengan penambahan serpihan kayu dapat meningkatkan $\mathrm{C} / \mathrm{N}$ ratio dan meningkatkan $\mathrm{pH}$ kompos hal ini disebabkan karena proses pengomposan berada pada kondisi aerobic (Ruslinda dan Aziz, 2004).

Sampah organik sangat melimpah di lingkungan rumah maupun yang berasal dari dalam rumah, tetapi kader Bank Sampah belum mampu mengelola sampah organik ini menjadi kompos yang memiliki nilai tersendiri terhadap lingkungan. Pengolahan bahan organik menjadi kompos membutuhkan Bioaktifator agar proses pengomposan lebih cepat, tetapi kader Bank Sampah belum paham bagaiman cara menggunakan bioaktifator tersebut, sehingga perlu adanya suatu pengenlan dan demonstrasi menggunakan bioaktifator tersebut agar berfungsi dalam mengurai sampah organik. Tujuan kegiatan ini adalah untuk meningkatkan pengetahuan mitra dengan penyadaran, dan demonstrasi, dan mengajak masyarakat mengelola sampah organik yang ada di lingkungannya untuk dijadikan kompos.

\section{METODE}

Kegiatan pengabdian masyarakat ini dilaksanakan dengan beberapa cara, antara lain: Penyadaran : kegiatan ini merupakan kegiatan yang sangat penting, karena sebelum mitra itu menyadari akan manfaat kompos, dan manfaat kompos, maka kegiatan ini tidak akan berhasil. Penyuluhan : kegiatan ini dilakukan setelah mitra merasa mereka membtuhkan ilmu yang akan diperoleh untuk memanfaatkan sampah organik menjadi kompos. Demonstrasi : kegiatan ini 
dilakukan untuk menunjukkan kepada mitra tentang contoh contoh pembuatan kompos dan sampah yang dihasilkan dari pekarangan maupun dari dapur rumah. Evaluasi : kegiatan ini dilakukan dengan menyebarkan kuesioner sebelum dan sesudak kegiatan dilakukan.

\section{HASIL DAN PEMBAHASAN}

Kegiatan dilaksanakan pada tanggal 10 Oktober 2018, lokasi kegiatan di gedung pertemuan Kelurahan Labuh Baru Timur, dihadiri oleh 30 peserta. Kegiatan dibuka oleh Lurah Kelurahan Labuh Baru Timur bapak Peri Susanto, SE., dan kegiatan penyuluhan ini dihadiri oleh Camat Kecamatan Payung Sekaki yaitu bapak Zarman Candra.

Peserta yang mengikuti kegiatan ini sangat antusias terutama pada saat kegiatan demonstrasi, seluruh peserta turut erta dalam mengolah sampah yang sudah dibawa untuk dijadikan kompos. Kendala yang dihadapi pada saat kegiatan adalah tidak adanya alat perajang bahan organik untuk dijadikan kompos, sehingga bahan organik yang akan dikomposkan ukurannya masih besar besar dan kasar, hal ini akan menghambat kecepatan pengomposan bahan tersebut.

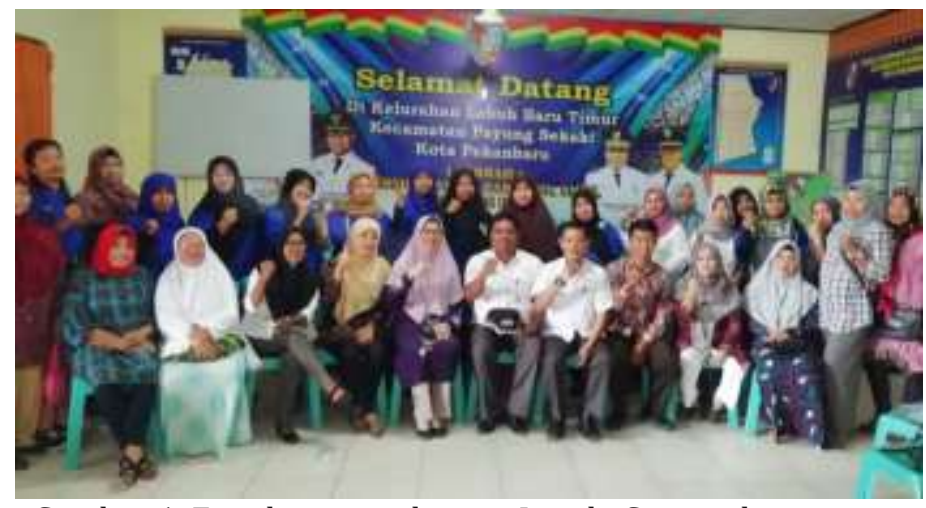

Gambar 1. Foto bersama dengan Lurah, Camat, dan peserta
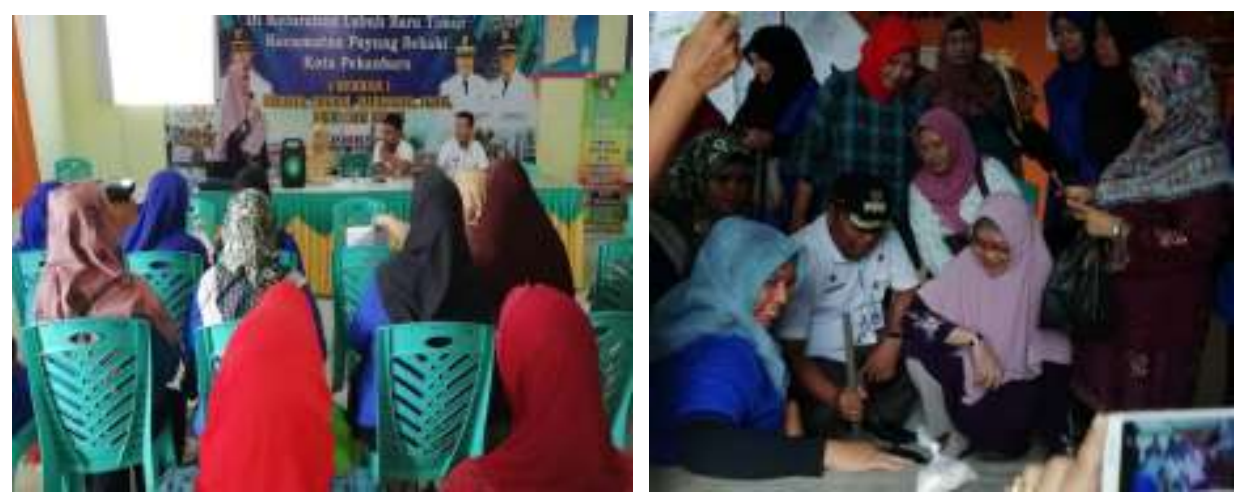

Gambar 2. Pelaksanaan kegiatan

(Sulistyorini, 2005) melaporkan bahwa bahan organik yang digunakan dalam pembuatan kompos harus kecil dan homogeny, karena semakin kecil ukuran bahan yang digunakan maka proses pengomposan akan semakin cepat, yang utama adalah aerasi dalam tumpukan bahan kompos harus terjaga, dan penambahan starter bahan organik dilakukan setiap hari dengan penambahan mikroba yang akan membantu mempercepat pengomposan.

Pada kegiatan pengabdian masyarakat ini Tim menggunakan bio aktifator EM 4. Berdasarkan laporan (Darmawati, 2015) bahwa EM 4 merupakan salah satu bio aktifator yang 
berpengaruh terhadap pengomposan limbah sayur dan dedaunan. (Widiyaningrum, 2015) melaporkan bahwa EM 4 yang digunakan dalam pengomposan menghasilkan penyusutan bahan organik yang paling tinggi, dibandingkan dengan bio aktifator yang lain.

Bahan organik yang digunakan salah satunya adalah sekam padi, dimana diketahui bahwa sekam padi merupakan bahan organik yang lama proses penguraiannya, tetapi menghasilkan aerasi yang baik di lingkungan pengomposan, dan menyebabkan kelembaban menjadi rendah. Seperti yang dilaporkan oleh (Ruslinda, 2004) bahwa penambahan serpihan kayu menyebabkan suhu dan kelembaban menjadi lebih rendah sehingga kondisi menjadi aerob, dan hal ini tidak dapat memenuhi kelembaban yang diharapkan yaitu di atas 50\%, dan pH tidak memenuhi persyaratan pengomposan.

Bahan kompos yang digunakan pada kegiatan ini tidak menggunakan kompos yang sudah jadi sebagai starternya. Anjuran pembuatan kompos starter digunakan baik itu berupa pupuk kandang atau kompos yang sudah jadi, agar proses pengomposan lebih cepat terlaksana, seperti yang dilaporkan oleh (Sahwan, 2011) kompos matang digunakan untuk menstimulir kerja komposter yang digunakan dalam menguraikan bahan organik yang dijadikan bahan kompos. Kompos yang baik akan mengalami penyusutan hampir 50\% dari berat semula, dan tetap lembab (Setyaningsih, 2017).

Hasil evaluasi kuesioner sebelum dan sesudah kegiatan ditampilkan pada Tabel berikut:

Tabel 1. Rekap kuesioner sebelum kegiatan

\begin{tabular}{|c|c|c|c|c|}
\hline \multirow{2}{*}{ Kuesioner } & \multicolumn{4}{|c|}{ Jawaban (\%) } \\
\hline & a & $\mathrm{b}$ & $\mathrm{c}$ & $\mathrm{d}$ \\
\hline Mengikuti pelatihan & 11 & 89 & & \\
\hline Manfaat limbah rumahtangga & 5 & 63 & 0 & 32 \\
\hline Manfaat pupuk kompos & 11 & 0 & 26 & 63 \\
\hline Bahan kompos & 11 & 79 & 11 & 0 \\
\hline Bioaktifator EM 4 & 58 & 5 & 0 & 37 \\
\hline Ciri-ciri kompos matang & 11 & 26 & 21 & 42 \\
\hline Alat yang digunakan & 0 & 84 & 5 & 11 \\
\hline Manfaat gula dalam pengomposan & 5 & 21 & 63 & 11 \\
\hline Lokasi pengomposan & 26 & 21 & 63 & 11 \\
\hline $\begin{array}{l}\text { Kesediaan memanfaatkan limbah } \\
\text { untuk pembuatan kompos }\end{array}$ & 100 & 0 & 0 & 0 \\
\hline
\end{tabular}

Pada umumnya peserta belum mengikuti pelatihan pembuatan kompos dari sampah rumahtangga, dan manfaat limbah rumahtangga untuk dijadikan kompos juga belum banyak diketahui, pengetahuan peserta tentang pupuk organik dan anorganik juga sangat minim sekali, sehingga kegiatan yang dilakukan perlu dilanjutkan dengan kegiatan berikutnya. Sampah yang ada disekitar rumah atau sampah rumahtangga perlu penanganan yang tuntas agar lingkungan terjaga dan asri, kegiatan yang incidental belum dapat menuntaskan masalah yang dihadapi, kegiatan ini baru dapat meningkatkan pengetahuan peserta dalam mengolah sampah menjadi kompos.

Tabel 2. Rekap kuesioner sesudah kegitan

\begin{tabular}{lcccc}
\hline \multicolumn{1}{c}{ Kuesioner } & \multicolumn{3}{c}{ Jawaban (\%) } \\
\hline Mengikuti pelatihan & $\mathrm{a}$ & $\mathrm{b}$ & $\mathrm{c}$ & $\mathrm{d}$ \\
Manfaat limbah rumahtangga & 10 & 0 & 0 & 0 \\
Manfaat pupuk kompos & 0 & 67 & 0 & 33 \\
Bahan kompos & 33 & 0 & 0 & 67 \\
Bioaktifator EM 4 & 0 & 10 & 0 & 0 \\
\hline
\end{tabular}




\begin{tabular}{lcccc}
\hline Ciri-ciri kompos matang & 0 & 0 & 0 & 10 \\
Alat yang digunakan & 0 & 10 & 0 & 0 \\
Manfaat gula dalam pengomposan & 10 & 0 & 0 & 0 \\
$\begin{array}{l}\text { Lokasi pengomposan } \\
\text { Kesediaan memanfaatkan limbah }\end{array}$ & 0 & 0 & 33 & 67 \\
untuk pembuatan kompos & 10 & 0 & 0 & 0 \\
\hline
\end{tabular}

Tabel 3. Peningkatan pengetahuan setelah kegiatan

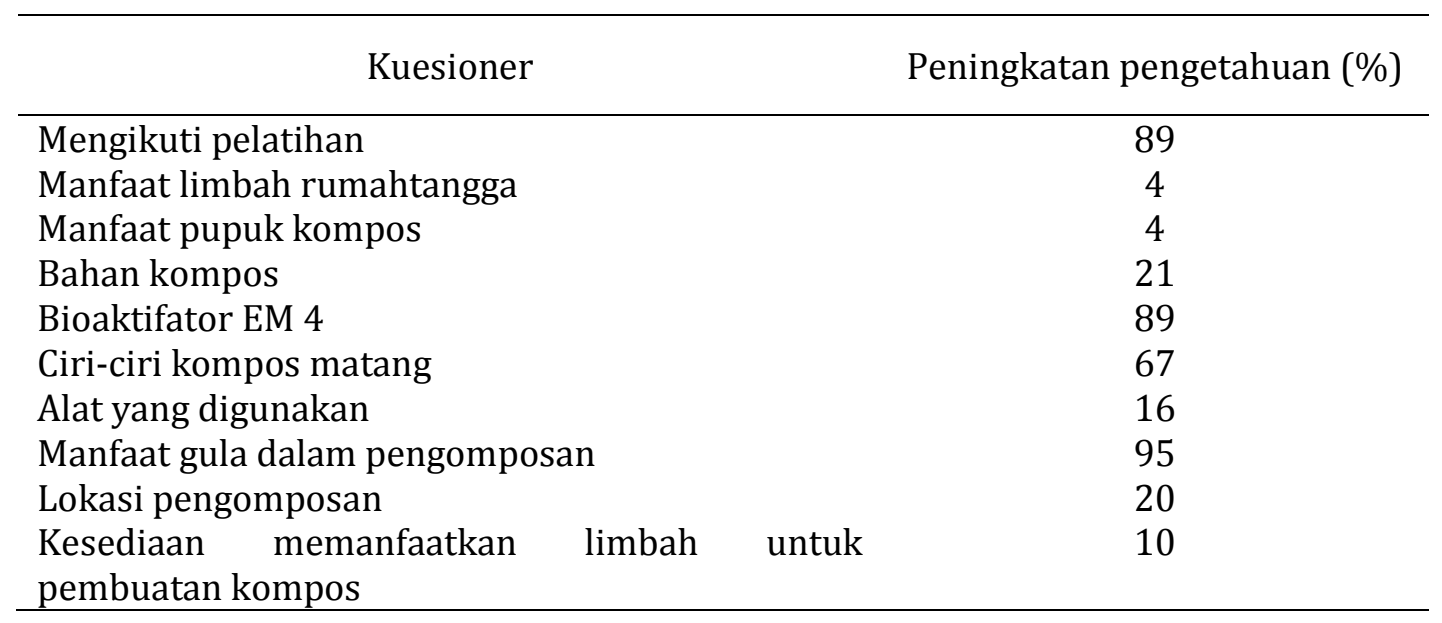

Kegiatan yang dilakukan meningkatkan pengetahuan peserta seperti yang tercantum pada Tabel 3. Peningkatan yang terjadi berkisar antara $4 \%-95 \%$, peningkatan yang beragam sesuai dengan pengetahuan peserta dan keseriusan peserta dalam menyimak penjelasan yang diberikan. (Suprapto, 2017) melaporkan bahwa kurangnya pengetahuan masyarakat tentang penangan limbah menjadi sesuatu yang bermanfaat perlu sosialisasi yang berkesinambungan. (Suhastyo, 2017) melaporkan bahwa terjadi peningkatan pengetahuan peserta dan peningkatan ketrampilan dalam memanfaatkan bahan organik menjadi kompos.

\section{KESIMPULAN}

Hasil kegiatan disimpulkan dapat meningkatan pengetahuan, pemahaman, dan ketrampilan peserta berkisar antara 4\%-95\%. Dan kecepatan pengomposan sangat tergantung dari ukuran bahan organik yang dijadikan bahan untuk kompos, semakin kecil ukuran potongan bahan organik maka proses pengomposan akan semakin cepat. Bio aktifator yang digunakan berperan dalam mempercepat proses pengomposan, selain itu kehomogenan bahan juga menjadi pertimbangan dalam pengomposan.

\section{UCAPAN TERIMA KASIH}

Ucapan terimakasih ditujukan kepada Lurah Labuh Baru Timur yang telah memberikan kesempatan untuk melakukan kegiatan pengabdian di wilayah administratifnya, dan terimakasih diucapkan kepada pimpinan Unilak yang telah memberikan bantuan finansial dalam melaksanakan kegiatan ini. 


\section{DAFTAR PUSTAKA}

Darmawati. (2015). Efektivitas Berbagai Bioaktivator Terhadap Pembentukan Kompos Dari Limbah Sayur Dan Daun. J. Dinamika, XXX(2), 93-100.

Ruslinda, Y., dan Aziz, R. (2004). Pengaruh Penambahan Serpihan Kayu Terhadap Kualitas Kompos Sampah Organik Sejenis Dalam Komposter Rumah Tangga. J.Teknik Lingkungan, 14(1), 13-22.

Sahwan, F. L., dan Wahyono, S. (2011). Kualitas Kompos Sampah Rumah Tangga Yang Dibuat Dengan Menggunakan "Komposter" Aerobik. J. Teknik Lingkungan, 12(3), 233-240.

Setyaningsih, E., Astuti, D. S., Astuti, R., Biologi, D. P., \& Surakarta, U. M. (2017). Kompos Daun Solusi Kreatif Pengendali Limbah. J. Bioeksperimen, 3(2), 45-51.

Sinartani, (2011). Pupuk Organik dari Limbah Organik Sampah Rumah Tangga. Agroinovasi, $3(3417)$.

Suhastyo, A. A., Agroteknologi, P. S., Banjarnegara, P., dan Tengah, J. (2017). Pemberdayaan Masyarakat Melalui Pelatihan Pembuatan Pupuk Kompos. J.Pengabdian Dan Pemberdayaan Masyarakat, 1(2).

Sulistyorini, L. (2005). Pengelolaan Sampah Dengan Cara Menjadikannya Kompos. J. Kesehatan Lingkungan, 2(1), 77-85.

Suprapto, P. K., Ali, M., dan Nuryadin, E. (2017). Program Pengenalan Dan Sosialisasi Penerapan Teknologi Olah Sampah Organik Rumah Tangga (Osama) Di Kampung Jati Kabupaten Ciamis. J. Pengabdian Siliwangi, 3(1), 180-186.

Widiyaningrum, P. (2015). Efektivitas Proses Pengomposan Sampah Daun Dengan Tiga Sumber Aktivator Berbeda. J.Rekayasa, 13(19), 107-113. 